\title{
Kinobeon A, purified from cultured safflower cells, is a novel and potent singlet oxygen quencher ${ }^{\star}$
}

\author{
Yasuhiro Kambayashi ${ }^{1,2}$, Susumu Takekoshi ${ }^{3}$, Minoru Nakano ${ }^{2 \star}$, Masafumi \\ Shibamori ${ }^{1,4}$, Yoshiaki Hitomi $^{1}$ and Keiki Ogino ${ }^{1 凶}$ \\ ${ }^{1}$ Department of Environmental and Preventive Medicine, Graduate School of Medical Science, Kanazawa Uni- \\ versity, Ishikawa, Japan; ${ }^{2}$ Department of Photon and Free Radical Research, Japan Immunoresearch Laboratories, \\ Takasaki, Japan; ${ }^{3}$ Department of Pathology, Tokai University School of Medicine, Kanagawa, Japan; ${ }^{4}$ Third Insti- \\ tute of New Drug Discovery, Otsuka Pharmaceutical Co., Ltd., Tokushima, Japan; \\ ${ }_{e}$-mail: ogino@pub.m.kanazawa-u.ac.jp
}

Received: 10 August, 2005; revised: 8 September, 2005; accepted: 9 September, 2005

available on-line: 25 October, 2005

\begin{abstract}
We recently reported that kinobeon A, produced from safflower cells, suppressed the free radical-induced damage of cell and microsomal membranes. In the present study, we investigated whether kinobeon A quenches singlet oxygen, another important active oxygen species. Kinobeon $A$ inhibited the singlet oxygen-induced oxidation of squalene. The second-order rate constant between singlet oxygen and kinobeon $A$ was $1.15 \times 10^{10} \mathrm{M}^{-1} \mathrm{~s}^{-1}$ in methanol containing $10 \%$ dimethyl sulfoxide at $37^{\circ} \mathrm{C}$. Those of $\alpha$-tocopherol and $\beta$-carotene, which are known potent singlet oxygen quenchers, were $4.45 \times 10^{8} \mathrm{M}^{-1} \mathrm{~s}^{-1}$ and $1.26 \times 10^{10} \mathrm{M}^{-1} \mathrm{~s}^{-1}$, respectively. When kinobeon A was incubated with a thermolytic singlet oxygen generator, its concentration decreased. However, this change was extremely small compared to the amount of singlet oxygen formed and the inhibitory effect of kinobeon A on squalene oxidation by singlet oxygen. In conclusion, kinobeon A was a strong singlet oxygen quencher. It reacted chemically with singlet oxygen, but it was physical quenching that was mainly responsible for the elimination of singlet oxygen by kinobeon A. Kinobeon $\mathrm{A}$ is expected to have a preventive effect on singlet oxygen-related diseases of the skin or eyes.
\end{abstract}

Keywords: kinobeon A, singlet oxygen, antioxidant, quencher, endoperoxide, safflower

Active oxygen species, such as free radicals and singlet oxygen $\left({ }^{1} \mathrm{O}_{2}\right)$, induce cellular injury via the accumulation of oxidative damage to DNA, lipids, and protein, and/or by the induction of uncontrolled signal transduction (Halliwell \& Gutteridge, 1999; Klotz et al., 2000). Therefore, oxidative stress is suggested to be a cause of various diseases (Halliwell \& Gutteridge, 1999). On the other hand, antioxidants, such as $\alpha$-tocopherol, ascorbic acid and ubiquinol, protect biological systems from oxidative stress (Halliwell \& Gutteridge, 1999). We recently found a new antioxidant, kinobeon A (Kanehira et al., 2003). Kinobeon $\mathrm{A}$ is a unique red compound produced from safflower (Carthamus tinctorius L.) cells cultured under specific conditions (Wakayama et al., 1994) and has not been found in natural saf- flowers, other plants, animals or microorganisms. Safflower is a valuable plant used as an edible fat, as a Chinese medicine, in cosmetics, and in foodstuffs as a colorant. Kinobeon A inhibited the oxidation of rat liver microsomal membrane induced by the $\mathrm{Fe}^{2+}$-ADP/NADPH system, protected bovine kidney cell cultures from oxidative stress (hydrogen peroxide, tert-butyl hydroperoxide), and scavenged the superoxide anion produced in the hypoxanthine/xanthine oxidase system (Kanehira et al., 2003). However, the quenching of ${ }^{1} \mathrm{O}_{2}$ by kinobeon $\mathrm{A}$ is still not well established. In vivo, ${ }^{1} \mathrm{O}_{2}$ is produced by exposure to sunlight and from neutrophils and eosinophils. Neutrophils use ${ }^{1} \mathrm{O}_{2}$ when they kill bacteria to protect biological systems (Nakano et al., 1998; Tatsuzawa et al., 1998; 1999; 2000; Arisawa et

*Presented at the 26th Annual Meeting of The Japanese Society of Lipid Peroxide and Free Radical Research, October 2002, Tokushima, Japan, and the 73rd Annual Meeting of The Japanese Society of Hygiene, March 2003, Oita, Japan. ${ }^{\star}$ M. Nakano passed away in 2003.

Abbreviations: AMVN, 2,2'-azobis(2,4-dimethylvaleronitrile); $\mathrm{IC}_{50^{\prime}}$ half inhibitory concentration; $k_{\mathrm{Q}^{\prime}}$ second order rate constant for quenching; NEPO, 3-(4'-methyl-1'-naphthyl)-propionic acid, $1^{\prime}$, $4^{\prime}$-endoperoxide; ${ }^{1} \mathrm{O}_{2}$, singlet oxygen. 
al., 2003). On the contrast, ${ }^{1} \mathrm{O}_{2}$ is also considered to be a causative factor of various skin diseases and eye diseases (Halliwell \& Gutteridge, 1999). Therefore, the search for a novel effective ${ }^{1} \mathrm{O}_{2}$ quencher is important. ${ }^{1} \mathrm{O}_{2}$ is consumed by an antioxidant via a chemical addition reaction and/or physical quenching, such as electron transfer. Kinobeon A has many double bonds, which may be able to react with ${ }^{1} \mathrm{O}_{2}$. In the present study, we investigated the potential of kinobeon $\mathrm{A}$ as ${ }^{1} \mathrm{O}_{2}$ quencher.

\section{MATERIALS AND METHODS}

Materials. Squalene was purchased from Tokyo Chemical Industry Co., Ltd (Tokyo, Japan). $\alpha$-Tocopherol, $\beta$-carotene, isoluminol and microperoxidase were obtained from Sigma Chemical Co. (St. Louis, MO, USA). 2,2'-Azobis(2,4-dimethylvaleronitrile) (AMVN) was purchased from Wako Pure Chemical Industries, Ltd (Osaka, Japan). Kinobeon A was prepared as described previously (Wakayama et al., 1994). Solvents and other reagents were of the highest grade commercially available. 3-(4'-Methyl-1'-naphthyl)-propionic acid, 1',4'-endoperoxide (NEPO) was from Dr. Ken Fujimori (University of Tsukuba, Japan).

Effect of kinobeon $\mathrm{A}$, $\alpha$-tocopherol or $\beta$-carotene on ${ }^{1} \mathrm{O}_{2}$-induced squalene oxidation. Squalene was purified by HPLC using a CAPCELLPAK C18 column $(20 \times 250 \mathrm{~mm}, 5 \mu \mathrm{m}$, Shiseido Co. Ltd, Tokyo, Japan) and methanol as the mobile phase (flow rate: $10 \mathrm{ml} / \mathrm{min}$ ), as reported previously (Nakano et al., 1998). Purified squalene was dissolved in chloroform and stored at $-80^{\circ} \mathrm{C}$ prior to use. Kinobeon A was dissolved in dimethyl sulfoxide. The concentration of kinobeon A was calculated by using its molar absorption coefficient at $520 \mathrm{~nm}\left(1.95 \times 10^{5}\right.$ $\mathrm{M}^{-1} \mathrm{~cm}^{-1}$; our data). $\alpha$-Tocopherol and $\beta$-carotene were dissolved in methanol. The concentration of NEPO was calculated as previously reported (Nakano et al., 1998). After the solvent was removed from the chloroform solution of squalene under reduced pressure, methanol was added. The reaction was started by the addition of a NEPO solution (final concentration: $100 \mu \mathrm{M}$ ) to the mixture containing $1 \mathrm{mM}$ squalene and 1-100 $\mu \mathrm{M}$ kinobeon $\mathrm{A}, 10-1000$ $\mu \mathrm{M} \alpha$-tocopherol or $1-13 \mu \mathrm{M} \beta$-carotene in methanol/dimethyl sulfoxide (9:1, v/v; total volume: $1.0 \mathrm{ml})$ at $37^{\circ} \mathrm{C}$. An aliquot of the reaction mixture $(50 \mu \mathrm{l})$ was removed every $30 \mathrm{~min}$ for $90 \mathrm{~min}$ and injected into the HPLC using a CAPCELLPAK C18 (4.6 × 250 $\mathrm{mm}, 5 \mu \mathrm{m}$, Shiseido Co., Ltd, Tokyo, Japan) as an analytical column and methanol as the mobile phase (flow rate: $2 \mathrm{ml} / \mathrm{min}$ ). Squalene hydroperoxide was detected in a hydroperoxide-specific assay using the chemiluminescence of isoluminol (Yamamoto et al., 1987; Nakano et al., 1998).
Reaction between kinobeon $A$ and ${ }^{1} \mathrm{O}_{2}$ or AMVN-derived radical. Kinobeon A $(10 \mu \mathrm{M})$ was incubated with $1 \mathrm{mM}$ NEPO in methanol containing $10 \%$ dimethyl sulfoxide at $37^{\circ} \mathrm{C}$. AMVN $(1 \mathrm{mM})$ was also used instead of NEPO to compare the ${ }^{1} \mathrm{O}_{2}$ induced oxidation with the radical-induced oxidation of kinobeon A. An aliquot of the reaction mixture $(20 \mu \mathrm{l})$ was removed every $15 \mathrm{~min}$ for $75 \mathrm{~min}$ and injected into the HPLC system. A CAPCELLPAK C18 $(4.6 \times 250 \mathrm{~mm}, 5 \mu \mathrm{m})$ and methanol/water $(3: 2, \mathrm{v} / \mathrm{v})$ were used as a column and the mobile phase, respectively. The flow rate was $1.0 \mathrm{ml} / \mathrm{min}$. Kinobeon A was detected at $520 \mathrm{~nm}$.

Spectrophotometry. Kinobeon A $(10 \mu \mathrm{M})$ was incubated with $5 \mathrm{mM}$ NEPO in methanol containing $10 \%$ dimethyl sulfoxide at $37^{\circ} \mathrm{C}$. The UV-VIS absorption spectrum was measured (260-600 nm) every $10 \mathrm{~min}$ for $60 \mathrm{~min}$ using a spectrophotometer (U-3210, Hitachi Ltd, Tokyo, Japan).

\section{RESULTS}

Kinetic analysis of NEPO thermolysis in methanol containing $10 \%$ dimethyl sulfoxide at $37^{\circ} \mathrm{C}$

$\mathrm{NEPO}$, a thermolytic ${ }^{1} \mathrm{O}_{2}$ generator, was used in the present study. The kinetics of the decomposition of NEPO in methanol containing $10 \%$ dimethyl sulfoxide at $37^{\circ} \mathrm{C}$ was examined first, as described previously (Nakano et al., 1998), to clarify the total amount of ${ }^{1} \mathrm{O}_{2}$ formed by the thermal decomposition of NEPO in each experiment. The wavelength of the maximum absorbance $\left(\lambda_{\max }\right)$, molar absorption coefficient at $\lambda_{\max }$ of 3-(4'-methyl-1'-naphthyl)-propionic acid (a molecule remained after ${ }^{1} \mathrm{O}_{2}$ was produced from NEPO) and the first order rate constant of NEPO thermolysis were obtained as $287.4 \pm 0.6 \mathrm{~nm}$, $7800 \pm 70 \mathrm{M}^{-1} \mathrm{~cm}^{-1}$, and $(1.91 \pm 0.09) \times 10^{-4} \mathrm{~s}^{-1}$ (mean \pm S.D., $n=3)$, respectively. Since the thermolysis of $\mathrm{NEPO}$ is a first order reaction, the total amount of ${ }^{1} \mathrm{O}_{2}$ formed can be calculated using eqn. 1 .

$\left[{ }^{1} \mathrm{O}_{2}\right]_{\text {total }}=[\mathrm{NEPO}]_{0} \times\left(1-\exp \left(-1.91 \times 10^{-4} \times t\right)[\mathrm{M}](1)\right.$

where $\mathrm{t}$ (in seconds) stands for reaction time.

\section{Suppression of ${ }^{1} \mathrm{O}_{2}$-induced squalene oxidation by} kinobeon A

The effect of kinobeon $\mathrm{A}$ on the ${ }^{1} \mathrm{O}_{2}$-induced oxidation of squalene in organic solvent was investigated. Squalene was used since it is one of the most vulnerable lipids to ${ }^{1} \mathrm{O}_{2}$ (Nakano et al., 1998). Kinobeon A inhibited the ${ }^{1} \mathrm{O}_{2}$-induced oxidation of squalene dose-dependently (Fig. 1A). $\alpha$-Tocopherol and $\beta$-carotene, known as strong ${ }^{1} \mathrm{O}_{2}$ quenchers (Di 

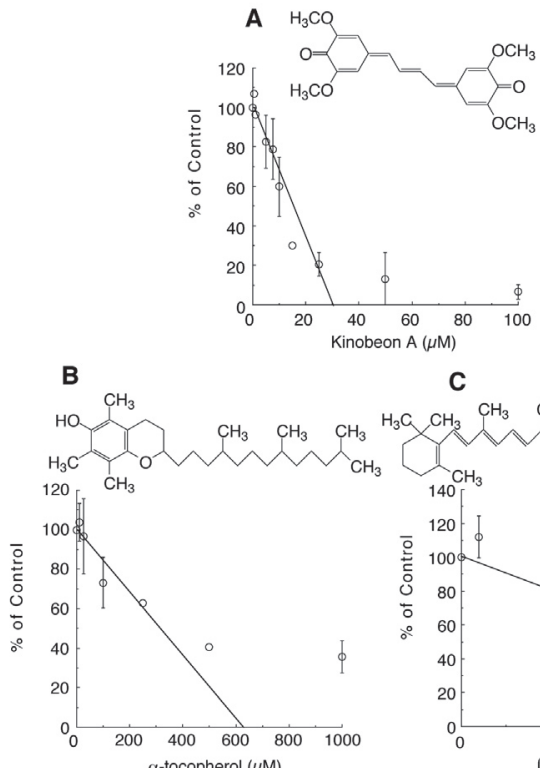

C

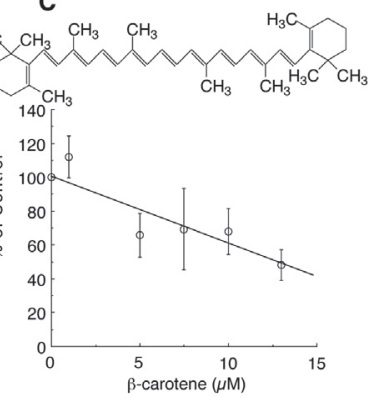

Figure 1. Inhibition of ${ }^{1} \mathrm{O}_{2}$-induced squalene oxidation by each quencher.

(A) Kinobeon A, (B) $\alpha$-tocopherol, and (C) $\beta$-carotene. Squalene $(1 \mathrm{mM})$ was incubated with $100 \mu \mathrm{M}$ NEPO and an ${ }^{1} \mathrm{O}_{2}$ quencher in methanol containing $10 \%$ dimethyl sulfoxide for $90 \mathrm{~min}$ at $37^{\circ} \mathrm{C}$. The ratio of squalene hydroperoxide formed in the presence of the quencher to that in its absence (control) is shown. Results are expressed as means \pm S.D. $(n=3)$. On some points, error bars are not seen since they are very small. The structure of each quencher is also shown.

Mascio et al., 1989; Kaiser et al., 1990; Tatsuzawa et al., 2000), were used to verify the quenching abilities of kinobeon A. They also inhibited the ${ }^{1} \mathrm{O}_{2}$-induced oxidation of squalene in a dose-dependent manner (Fig. 1B and C). The half inhibitory concentrations $\left(\mathrm{IC}_{50} \mathrm{~s}\right)$ of $\alpha$-tocopherol and $\beta$-carotene to ${ }^{1} \mathrm{O}_{2}$-induced oxidation of squalene in the present experimental system were $316 \mu \mathrm{M}$ and $13 \mu \mathrm{M}$, respectively (Table 1). That of kinobeon A was $15 \mu \mathrm{M}$ (Table 1). Thus, the $\mathrm{IC}_{50}$ of kinobeon $\mathrm{A}$ was similar to that of $\beta$-carotene and much smaller than that of $\alpha$-tocopherol. Judging from these results, kinobeon A can act as a potent ${ }^{1} \mathrm{O}_{2}$ quencher.

Kinetic analysis of reaction between each quencher and ${ }^{1} \mathrm{O}_{2}$

Moreover, second-order rate constants between ${ }^{1} \mathrm{O}_{2}$ and each quencher in methanol involving $10 \%$ dimethyl sulfoxide were roughly calculated using eqn. 2 (Young et al., 1971; Kohno et al., 1995).

$S_{0} / S_{\mathrm{Q}}=1+\left(k_{\mathrm{Q}} / k_{\mathrm{d}}\right)[\mathrm{Q}]$

where $S_{0}$ and $S_{\mathrm{Q}}$ represent slopes of the formation of squalene hydroperoxide plotted as a function of time in the absence and presence of each quencher,
Table 1. Second-order rate constants $\left(k_{\mathrm{Q}}\right)$ and $\mathrm{IC}_{50}$ between singlet oxygen and quencher in methanol containing $10 \%$ dimethyl sulfoxide at $37^{\circ} \mathrm{C}$

\begin{tabular}{lcl}
\hline Quencher & $\mathrm{IC}_{50}(\mu \mathrm{M})$ & $k_{\mathrm{Q}}\left(\mathrm{M}^{-1} \mathrm{~s}^{-1}\right)$ \\
\hline Kinobeon A & 15 & $1.15 \times 10^{10}$ \\
$\alpha$-Tocopherol & 316 & $4.45 \times 10^{8}$ \\
$\beta$-Carotene & 13 & $1.26 \times 10^{10}$ \\
\hline
\end{tabular}

respectively. $k_{\mathrm{d}}$ denotes the first-order rate constant of ${ }^{1} \mathrm{O}_{2}$ decay. In the present study, $1.8 \times 10^{5} \mathrm{~s}^{-1}\left(k_{\mathrm{d}}\right.$ in methanol) (Young et al., 1971) was used as the $k_{\mathrm{d}}$ for the calculation of second-order rate constant, since $k_{\mathrm{d}}$ is slightly lower in dimethyl sulfoxide (3.3-5.2 $\times$ $\left.10^{4} \mathrm{~s}^{-1}\right)$ than in methanol $\left(0.9-2.0 \times 10^{5} \mathrm{~s}^{-1}\right)$ (Bellus, 1978). [Q] and $k_{\mathrm{Q}}$ represent the initial concentration of each quencher and second-order rate constant of the reaction between ${ }^{1} \mathrm{O}_{2}$ and the quencher involving physical quenching and a chemical reaction, respectively. $k_{\mathrm{Q}}$ values in the present study were shown in Table 1. Reported $k_{\mathrm{Q}}$ values of $\alpha$-tocopherol and $\beta$-carotene were $2.5 \times 10^{8} \mathrm{M}^{-1} \mathrm{~s}^{-1}$ in n-butanol at $35^{\circ} \mathrm{C}$
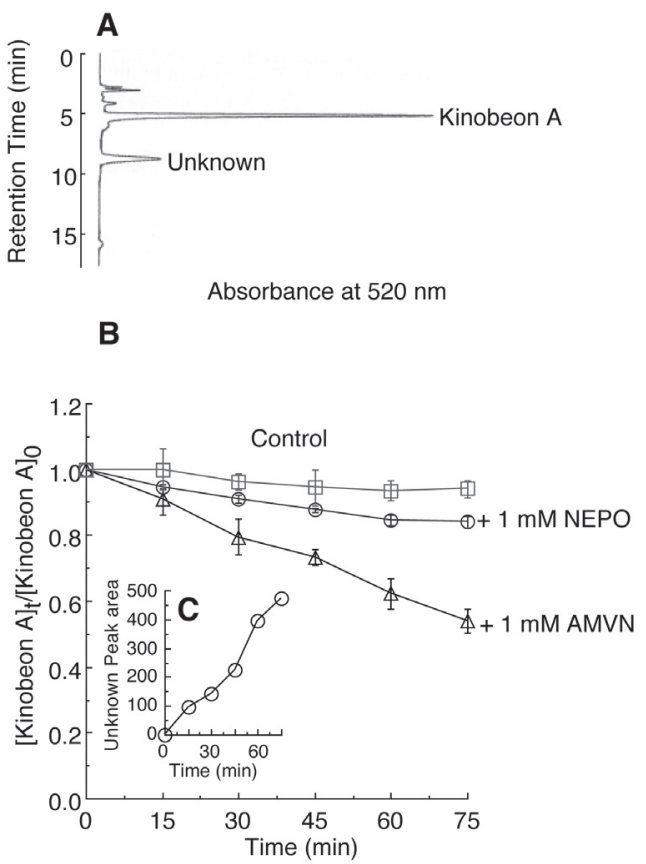

Figure 2. Reaction of kinobeon A with ${ }^{1} \mathrm{O}_{2}$ or peroxyl radical.

(A) Representative chromatogram from the kinobeon A analysis. Kinobeon A $(10 \mu \mathrm{M})$ was incubated with AMVN $(1 \mathrm{mM})$ in methanol containing $10 \%$ dimethyl sulfoxide at $37^{\circ} \mathrm{C}$. (B) Change in kinobeon A concentration during the incubation with $1 \mathrm{mM}$ NEPO or $1 \mathrm{mM}$ AMVN in methanol containing $10 \%$ dimethyl sulfoxide at $37^{\circ} \mathrm{C}$. A control experiment without NEPO or AMVN was also performed. Results are expressed as the ratio to the initial concentration of kinobeon A and as means \pm S.D. $(n=3)$. Squares: control; circles: $1 \mathrm{mM}$ NEPO; triangles: $1 \mathrm{mM}$ AMVN. (C) Change in the unknown peak area during the reaction between kinobeon A and $1 \mathrm{mM}$ AMVN. The initial concentration of kinobeon A was $10 \mu \mathrm{M}$. 
(Kohno et al., 1995) and $1.4 \times 10^{10} \mathrm{M}^{-1} \mathrm{~S}^{-1}$ in ethanol/ chloroform/water (50:50:1, by vol.) (Di Mascio et al., 1989), respectively. These values were comparable to those obtained in the present study, although a different kind of organic solvent was used. These data also showed the high potential of kinobeon $\mathrm{A}$ as an ${ }^{1} \mathrm{O}_{2}$ quencher.

\section{Reaction of kinobeon A with ${ }^{1} \mathrm{O}_{2}$}

The change in the concentration of $\mathrm{ki}$ nobeon A was followed using HPLC to elucidate the mechanism by which kinobeon A eliminates ${ }^{1} \mathrm{O}_{2}$ (Fig. 2A). The concentration of kinobeon $\mathrm{A}$ (retention time: $5.3 \mathrm{~min}$ ) decreased slightly during the incubation of $10 \mu \mathrm{M}$ kinobeon A with $1 \mathrm{mM}$ NEPO in methanol containing $10 \%$ dimethyl sulfoxide at $37^{\circ} \mathrm{C}$. This decrease was slightly greater than that in the control system without NEPO. The new peak, however, did not appear on the chromatograms. The concentration of kinobeon A was also decreased by $1 \mathrm{mM}$ AMVN, known as an oil-soluble radical initiator (Niki, 1990), in the same solvent at $37^{\circ} \mathrm{C}$. In this case, an unknown peak (Fig. 2A; retention time: 9 min) was observed and its area slightly increased time-dependently (Fig. 2C). It might be an oxidation product of kinobeon $\mathrm{A}$. The reaction between kinobeon $\mathrm{A}$ $(10 \mu \mathrm{M})$ and ${ }^{1} \mathrm{O}_{2}$ (5 mM NEPO) was also examined spectrophotometrically. Only a micromolar amount of kinobeon A was lost and new absorbance did not appear, although $2.49 \mathrm{mM}{ }^{1} \mathrm{O}_{2}$ had formed for $60 \mathrm{~min}$ at $37^{\circ} \mathrm{C}$ (not shown).

\section{DISCUSSION}

In the present study, we showed the potential of kinobeon $\mathrm{A}$ as an ${ }^{1} \mathrm{O}_{2}$ quencher. The total amount of ${ }^{1} \mathrm{O}_{2}$ formed for $90 \mathrm{~min}$ was $64.3 \mu \mathrm{M}$ (value obtained by calculation using eqn. 1) when $1 \mathrm{mM}$ squalene was incubated with $100 \mu \mathrm{M}$ NEPO in methanol containing $10 \%$ dimethyl sulfoxide at $37^{\circ} \mathrm{C}$. On the other hand, $1.02 \pm 0.28 \mu \mathrm{M}$ (mean \pm S.D., $n=9$ ) of squalene hydroperoxide was formed in 90 min. Approximately $1.59 \%$ of the ${ }^{1} \mathrm{O}_{2}$ formed contributed to the oxidation of squalene. Thus, the decay of ${ }^{1} \mathrm{O}_{2}$ was significantly faster than the rate of oxidation product formation from squalene by ${ }^{1} \mathrm{O}_{2}$. It was reported that the rate constants of ${ }^{1} \mathrm{O}_{2}$ decay were $0.9-2.0 \times 10^{5} \mathrm{~s}^{-1}$ and $3.3-5.2 \times 10^{4} \mathrm{~s}^{-1}$ in methanol and dimethyl sulfoxide, respectively (Bellus, 1978). The $k_{\mathrm{Q}}$ of squalene was reported to be $2.66 \times$ $10^{6} \mathrm{M}^{-1} \mathrm{~s}^{-1}$ in $\mathrm{n}$-butanol at $35^{\circ} \mathrm{C}$ (Kohno et al., 1995). Since $1 \mathrm{mM}$ squalene was used in the present study, the $k_{\mathrm{Q}}[\mathrm{Q}]$ was $2.66 \times 10^{3} \mathrm{~s}^{-1}$. These values were consistent with the present results, although different solvents were used in each system.

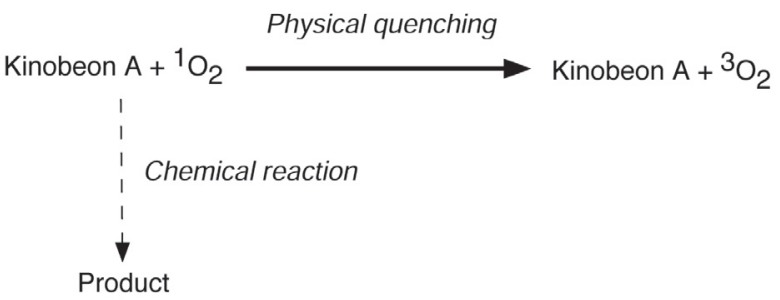

Scheme 1. Proposed pathway of scavenging of singlet oxygen by kinobeon A.

The total amount of ${ }^{1} \mathrm{O}_{2}$ formed from $1 \mathrm{mM}$ NEPO in $75 \mathrm{~min}$ in this experimental system was $577 \mu \mathrm{M}$. The loss of kinobeon A within $75 \mathrm{~min}$ in this system was $0.99 \mu \mathrm{M}$. If ${ }^{1} \mathrm{O}_{2}$ reacts with kinobeon $\mathrm{A}$ at a ratio of $1: 1,0.17 \%$ of the ${ }^{1} \mathrm{O}_{2}$ formed was consumed by kinobeon $\mathrm{A}$. This value was extremely small in comparison with the inhibitory efficiency of kinobeon $\mathrm{A}$ on the ${ }^{1} \mathrm{O}_{2}$-induced oxidation of squalene, even if most ${ }^{1} \mathrm{O}_{2}$ was lost via decay (quenching by organic solvent). Therefore, most of the ${ }^{1} \mathrm{O}_{2}$ consumed by kinobeon $\mathrm{A}$ would be physically quenched without a chemical reaction under the present conditions.

On the other hand, a $46.1 \%$ decrease in kinobeon A was observed in methanol containing 10\% dimethyl sulfoxide during the incubation of $10 \mu \mathrm{M}$ kinobeon A with $1 \mathrm{mM}$ AMVN for $75 \mathrm{~min}$ at $37^{\circ} \mathrm{C}$. The initial rate of peroxyl radical formation from AMVN was calculated as follows; $R_{\mathrm{i}}=2 e k_{\mathrm{d}}[\mathrm{AMVN}]$; the initial rate of the thermal decomposition of AMVN was estimated to be approximately linear, since AMVN has a long half-life (2.8 days, calculated from reference (Niki et al., 1986)). $R_{\mathrm{i},}, e$ and $k_{\mathrm{d}}$ stand for the initial rate of peroxyl radical formation by AMVN thermolysis, the efficiency of free radical generation from AMVN and the rate constant of decomposition of AMVN, respectively. The $e k_{\mathrm{d}}$ in benzene at $37^{\circ} \mathrm{C}$ is $2 \times 10^{-6} \mathrm{~s}^{-1}$ (Niki et al., 1986). Therefore, $R_{\mathrm{i}}$ is calculated from the equation; $4 \times 10^{-6} \times$ [AMVN] $\left(\mathrm{Ms}^{-1}\right)$. Eighteen micromolar peroxyl radical is formed from $1 \mathrm{mM}$ AMVN in benzene for 75 $\mathrm{min}$ at $37^{\circ} \mathrm{C}$. This value would not be significantly different from that obtained in methanol containing $10 \%$ dimethyl sulfoxide. The total amount of peroxyl radicals formed in the AMVN system would be much smaller than that of ${ }^{1} \mathrm{O}_{2}$ formed in the NEPO system, even if the kinetic chain length was about 10. On the basis of the above result, kinobeon A can trap (peroxyl) radicals efficiently. This is consistent with the finding that kinobeon A inhibited the oxidative damage to rat liver microsomal membrane induced by $\mathrm{Fe}^{2+}$-ADP/NADPH (Kanehira et al., 2003). These results show that kinobeon A chemically reacts efficiently with the peroxyl radical, but only slightly with ${ }^{1} \mathrm{O}_{2}$.

The present study shows that kinobeon A can react chemically with ${ }^{1} \mathrm{O}_{2}$, but mainly quenches 
${ }^{1} \mathrm{O}_{2}$ via an energy transfer or electron transfer mechanism (physical quenching; Scheme 1). In conclusion, kinobeon $\mathrm{A}$ is a potent ${ }^{1} \mathrm{O}_{2}$ quencher. Therefore, it is expected to be a valuable reagent for ${ }^{1} \mathrm{O}_{2}$-related disorders, such as skin and eye disease.

\section{Acknowledgements}

This work was supported in part by Grantin-Aid for Scientific Research (B) 14370120 from the Ministry of Education, Culture, Sports, Science and Technology of the Japanese Government.

\section{REFERENCES}

Arisawa F, Tatsuzawa H, Kambayashi Y, Kuwano H, Fujimori K, Nakano M (2003) MCLA-dependent chemiluminescence suggests that singlet oxygen plays a pivotal role in myeloperoxidase-catalyzed bactericidal action in neutrophil phagosomes. Luminescence 18: 229-238.

Bellus D (1978) Quenchers of singlet oxygen. In Singlet Oxygen, Reactions with Organic Compounds and Polymers. Randy B, Rabek JF, eds, pp 61-110. Wiley-Intersciencs, Chichester.

Di Mascio P, Kaiser S, Sies H (1989) Lycopene as the most efficient biological carotenoid singlet oxygen quencher. Arch Biochem Biophys 274: 532-538.

Halliwell B, Gutteridge JMC (1999) Free Radicals in Biology and Medicine, 3rd edn. Oxford University Press, New York, Oxford.

Kaiser S, Di Mascio P, Murphy ME, Sies H (1990) Physical and chemical scavenging of singlet molecular oxygen by tocopherols. Arch Biochem Biophys 277: 101-108.

Kanehira T, Takekoshi S, Nagata H, Matsuzaki K, Kambayashi Y, Osamura RY, Homma T (2003) A novel and potent biological antioxidant, Kinobeon A, from cell culture of safflower. Life Sci 74: 87-97.

Klotz L-R, Briviba K, Sies H (2000) Signaling by singlet oxygen in biological systems. In Antioxidant and Redox Regulation of Genes. Sen CK, Sies H, Baeuerle PA, eds, pp 1-20, Academic Press, CA.
Kohno Y, Egawa Y, Itoh S, Nagaoka S, Takahashi M, Mukai K (1995) Kinetic study of quenching reaction of singlet oxygen and scavenging reaction of free radical by squalene in n-butanol. Biochem Biophys Acta 1256: 52-56.

Nakano M, Kambayashi Y, Tatsuzawa H, Komiyama T, Fujimori K (1998) Useful ${ }^{1} \mathrm{O}_{2}\left({ }^{1} \Delta_{\mathrm{g}}\right)$ generator, 3-(4'-methyl-1'-naphthyl)-propionic acid, 1',4'-endoperoxide (NEPO), for dioxygenation of squalene (a skin surface lipid) in an organic solvent and bacterial killing in aqueous medium. FEBS Lett 432: 9-12.

Niki E (1990) Free radical initiators as source of water- or lipid-soluble peroxyl radacals. Methods Enzymol 186: 100-108.

Niki E, Tsuchiya J, Yoshikawa Y, Yamamoto Y, Kamiya Y (1986) Oxidation of lipids. XIII. Antioxidant activities of $\alpha-, \beta-, \gamma-$, and $\delta$-tocopherol. Bull Chem Soc Jpn 59: 497-501.

Tatsuzawa H, Maruyama N, Misawa N, Fujimori K, Hori K, Sano Y, Kambayashi Y, Nakano M (1998) Inactivation of bacterial respiratory chain enzymes by singlet oxygen. FEBS Lett 439: 329-333.

Tatzuzawa H, Maruyama T, Hori K, Sano Y, Nakano M (1999) Singlet oxygen $\left({ }^{1} \Delta_{2} \mathrm{O}_{2}\right)$ as the principal oxidant in myeloperoxidase-mediated bacterial killing in neutrophil phagosome. Biochem Biophys Res Commun 262: 647-650.

Tatsuzawa H, Maruyama T, Misawa N, Fujimori K, Nakano M (2000) Quenching of singlet oxygen by carotenoids produced in Escherichia coli - attenuation of singlet oxygen-mediated bacterial killing by carotenoids. FEBS Lett 484: 280-284.

Wakayama S, Kusaka K, Kanehira T, Yamada Y, Kawazu K, Kobayashi A (1994) Kinobeon A, a novel red pigment produced in safflower tissue cultures systems. Z Naturforsch 49c: $1-5$.

Yamamoto Y, Brodsky MH, Baker JC, Ames AN (1987) Detection and characterization of lipid hydroperoxides at picomole levels by high-performance liquid chromatography. Anal Biochem 160: 7-13.

Young RH, Wehrly K, Martin RL (1971) Solvent effects in dye-sensitized photooxidation reactions. J Am Chem Soc 93: 5774-5779. 